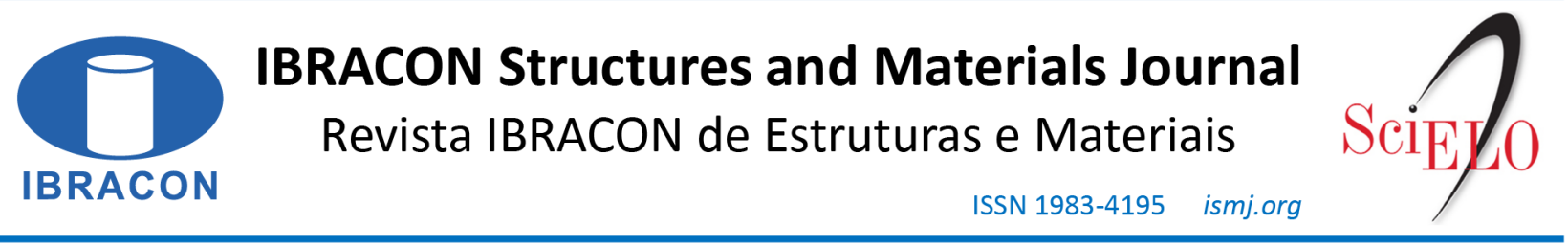

ORIGINAL ARTICLE

\title{
Second-order torsion effects in concrete buildings
}

\section{Efeitos de torção de segunda-ordem em edifícios de concreto}

\author{
Rodrigo Bezerra Andrade ${ }^{\mathrm{a}}$ \\ Petrus Gorgônio Bulhões da Nóbrega ${ }^{a}$ (D)
}

${ }^{\text {a }}$ Universidade Federal do Rio Grande do Norte - UFRN, Centro de Tecnologia, Campus Universitário, Lagoa Nova, Natal, RN, Brasil

Received 22 March 2019

Accepted 25 May 2020

\begin{abstract}
The internal forces due to torsion in global analysis of buildings, and its second-order effects, usually are not properly considered in structural design or even in design code's prescriptions. Although the $\gamma_{Z}$ coefficient, which is used to the evaluation of global second-order effects, has a wide, useful and consolidated application, it is true that specific torsional aspects are not well considered by it. This paper discusses the little-known $\gamma_{\theta}$ coefficient, an analogous proposition to the $\gamma_{Z}$ coefficient, but focused specifically on the consideration of torsional effects. After the discussion on the concepts and the design methodology, several buildings are evaluated and their displacements and the coefficients $\gamma_{\mathrm{Z}}$ and $\gamma_{\theta}$ are calculated. Comparing these parameters, and also the results obtained by the $\mathrm{P}-\Delta$ method, it is demonstrated the importance and the reliability of the $\gamma_{\theta}$ coefficient.
\end{abstract}

Keywords: torsion, second-order effect, global analysis.

Resumo: Os esforços torcionais na análise global de edifícios, e seus respectivos efeitos de segunda-ordem, usualmente não são adequadamente considerados, seja na prática de projetos ou mesmo nas prescrições normativas. Embora o coeficiente $\gamma_{Z}$ de avaliação dos esforços globais de segunda-ordem tenha uma larga, útil e consolidada aplicação, é fato que os aspectos específicos de torção não são bem representados por este parâmetro. Este artigo discute o pouco difundido coeficiente $\gamma_{\theta}$, proposta análoga ao $\gamma_{\mathrm{Z}}$, voltado especificamente para a consideração dos efeitos rotacionais. Após a discussão dos conceitos e da metodologia de cálculo, diversos edifícios são avaliados, calculando-se seus deslocamentos e os parâmetros $\gamma_{Z}$ e $\gamma_{\theta}$, comparando-os entre si e com os resultados obtidos pelo método $\mathrm{P}-\Delta$, demonstrando, dessa forma, a importância e a confiabilidade do coeficiente $\gamma_{\theta}$.

Palavras-chave: torção, efeito de segunda-ordem, análise global.

How to cite: R. B. Andrade, and P. G. B. Nóbrega, "Second-order torsion effects in concrete buildings", Rev. IBRACON Estrut. Mater, vol. 14, no. 1, e14105, 2020, https://doi.org/10.1590/S1983-41952021000100005

\section{INTRODUCTION}

The classical structural analysis, as generally used in civil engineering applications, considers the first-order effects to simplify its evaluation. Based on this assumption, the analysis of the structure occurs at its original configuration (Fusco and Onishi [1]). However, it is evident that the structural element's deformation cause new internal forces, the so-called secondorder effects. These are unavoidable, and for slender structures they should not be neglected, that is, the structure's final configuration should not be regarded as the same as its initial configuration (Wight and MacGregor [2]).

Kimura [3] affirms that the global stability of a structure is inversely proportional to its sensitivity to second-order effects. Obviously, in many usual concrete-made buildings with relatively small height and beam spans, the secondorder effects tends to be insignificant when compared with those of first-order. In such cases, they may be neglected.

In tall concrete buildings, typical second-order effects essentially derive from the horizontal actions, especially wind and earthquakes. Furthermore, the geometrical imperfections result in two types of second-order effects: the local and 
the global ones. Local effect refers to a specific structural element which presents a geometric deviation (columns, essentially), and the global effect concerns to the whole structure out-of-plumbness.

It is important to notice that other factors, besides horizontal actions, may give rise to the second-order effects. Vertical actions are also capable of causing horizontal displacements in some cases, such as: (a) when buildings are non-symmetrical, either by geometry or stiffness distribution (irregular placement of columns in the horizontal plane and/or asymmetrical shear walls); (b) when there are non-symmetrical elements acting as cantilevers at one side of the building (which impose unilateral displacements); or (c) when there are floating columns or columns with a great crosssection change, which also modifies the whole system's stiffness (Moncayo [4]). All these cases may present relevant horizontal displacements and, consequently, second-order effects.

The importance of the global second-order effects in tall concrete buildings can be determined by the use of the $\gamma_{Z}$ coefficient, whose design procedure is already established in ABNT NBR 6118:2014 prescriptions [5]. This is a dimensionless term, developed and originally presented in English by the celebrated Brazilian engineers Franco and Vasconcelos [6]. Its first version in Portuguese was published several years later (Franco and Vasconcelos [7]). This coefficient, of admirable simplicity and representativeness, is widely spread and consolidated in literature, and it is a function of the building's fundamental characteristics, such as height, stiffness and internal forces amplitude, being used to determine approximately the magnitude of global second-order effects.

The $\gamma_{Z}$ coefficient is absolutely useful as an indicator of instability, as it is especially practical to obtain and to use. However, as a simplified parameter, it may present a variable accuracy in its representation of the global second-order effects when compared to results obtained by applying more rigorous and precise methods.

In the last few years, some studies have compared the $\gamma_{Z}$ coefficient with other variables that were idealized for the same purpose. Vieira et al. [8] verify the $\gamma_{Z}$ efficacy as a global stability parameter, relating it to the critical global buckling load factor $(\lambda)$ and its respective critical instabilities modes. Generally, satisfactory results were obtained, but the $\gamma_{Z}$ coefficient inefficacy becomes clear when the critical mode is a torsional configuration.

Following another idea, Mamone et al. [9] define a $\chi_{t}$ parameter, based on the natural vibration period and on the geometrical characteristics of the building, which is used as an indicator of susceptibility to second-order effects and as a factor of amplification of first-order moments in the structure, in the same way as the $\gamma_{Z}$ coefficient. Reis et al. [10] expand and modify Mamone et al. [9] work, using the denomination $\chi_{\mathrm{T}}$ for the amplification parameter proposed to substitute the $\gamma_{Z}$ coefficient.

Leitão et al. [11] follow the development of the $\chi_{\mathrm{T}}$ parameter, focusing specially in structures with geometric asymmetry and with vibration fundamental mode of torsional shape. The results of the simplified analysis are compared with those obtained through non-linear numerical analysis considering the $\mathrm{P}-\Delta$ effect.

Recently, Cunha et al. [12] proposed a new simplified parameter $\left(\zeta_{\mathrm{g}}\right)$ in order to consider the global second-order effects, based on the Galerkin Method, and with the same application of the $\gamma_{Z}$ coefficient.

Clearly, the $\gamma_{Z}$ coefficient considers essentially the second-order effects due to the building flexure behavior, which result in translation of its floors. However, it is known that, besides the translational displacements, the building is also subjected to rotational effects, generated by factors such as asymmetrical horizontal forces acting on its sides, the unavoidable misalignment between the center of loadings and the center of stiffness of the structure, among others. Such rotational displacements are also capable of producing second-order effects, which are not completely encompassed by the $\gamma_{Z}$ coefficient.

An alternative for the consideration of the torsional global second-order effects, in a simplified and efficient manner, was proposed by Franco [13], [14]: the $\gamma_{\theta}$ coefficient. This is a parameter analogous to the $\gamma_{Z}$ coefficient, but specifically used to measure the global second-order effects caused by rotational displacements of the building. It is surprising that, despite the elapsed time since it was originally proposed, this parameter is still relatively unknown, especially when considering its potential application. There is no related study that has researched the $\gamma_{\theta}$ coefficient, whether in technical literature or in design standards, besides the two already mentioned papers written by Mario Franco, one of the geniuses behind the $\gamma_{\mathrm{Z}}$ coefficient, who recently passed away on September 2019.

The main purpose of this paper is to rescue and to divulgate this important contribution of a simplified formulation whose features are the precision and the reliability. After the discussion on the concepts and the design methodology, several regular and irregular buildings are evaluated. Their displacements, $\gamma_{Z}$ and $\gamma_{\theta}$ coefficients are calculated, and the results are compared to each other and to those obtained from the $\mathrm{P}-\Delta$ method.

In Franco's own words [14], structural engineers take a concerned look to ensure, in two orthogonal directions, the required strength and flexural stiffness to the building. However, not always these panels provide the necessary torsional stiffness. Evidently, such cases should be investigated with the same rigor as commonly applied in flexural analysis. 


\section{EXPRESSIONS FOR $\gamma_{\mathrm{Z}}$ AND $\gamma_{\Theta}$, CONCEPTS AND CORRELATION}

\section{$2.1 \gamma \mathrm{z}$ coefficient}

As already mentioned, the $\gamma_{Z}$ coefficient is used for the evaluation of global second-order effects in tall buildings, and it represents the ratio between final internal forces in the structure and those obtained in a first-order linear analysis. This relation can be used as an amplification factor to the first-order effects to obtain the final results.

This term was developed by Franco and Vasconcelos [6], [7] considering that, in successive iterations of the secondorder analysis, the proportion between forces is constant, that is, these forces grow according to a geometric progression. Based on this premise, the coefficient is given by Equation 1:

$\gamma_{Z}=\frac{M_{2}}{M_{1}}=\frac{1}{1-\frac{\Delta M_{1}}{M_{1}}}$

where:

$\mathrm{M}_{1}=$ Global first-order bending moment;

$\mathrm{M}_{2}=$ Global total bending moment;

$\Delta \mathrm{M}_{1}=$ Increment of global bending moment, due to first-order displacements.

Equation 1 is an exact numerical expression for $\mathrm{M}_{2}$ if the ratio between the incremental force $\Delta \mathrm{M}_{1}$ and the firstorder force $\mathrm{M}_{1}$ is kept proportional for any of the additional forces $\Delta \mathrm{M}_{\mathrm{i}}$ and its respective term $\Delta \mathrm{M}_{\mathrm{i}-1}$ in any iteration. This is a particular property of framed structures in linear analysis (without cracking effects) where the geometric proportionality is observed between bending moments of two consecutive steps of the process.

The $\gamma_{Z}$ coefficient application may be illustrated in the classical problem of a cantilever beam subjected to vertical and horizontal forces, according to Figure 1. In this case, the bending moment increment $\Delta \mathrm{M}_{1}$ in the structure's base is the product of the eccentricity $\mathrm{e}_{1}$, due to the displacement produced by the horizontal force $\mathrm{V}$, and the vertical force $\mathrm{P}$. The relation between $\Delta \mathrm{M}_{1}$ and $\mathrm{M}_{1}$ expresses the proportion between the increment of internal forces and the global first-order moment, as in Equation 1.

a)

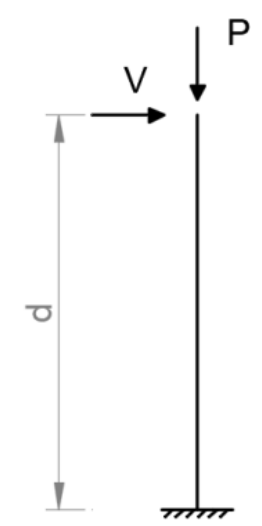

b)

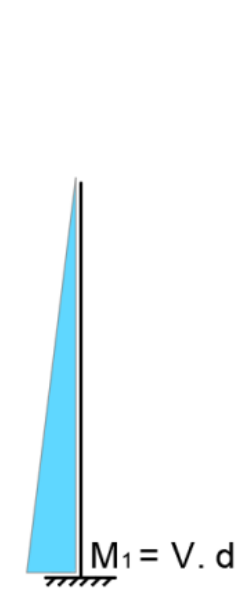

c)

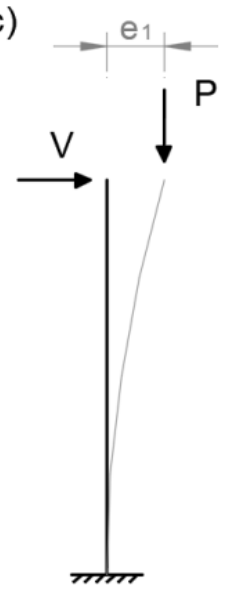

d)

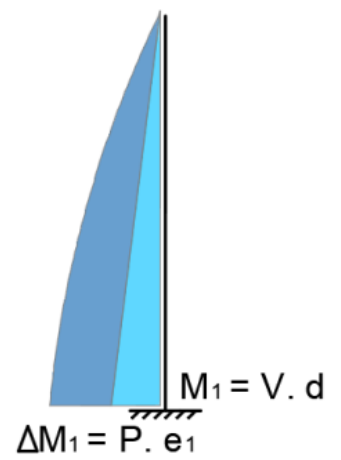

Figure 1. a) Cantilever beam. b) First-order internal forces. c) Beam displacement. d) Internal forces considering second-order effects.

\section{$2.2 \gamma_{\theta}$ coefficient}

After the development of the $\gamma_{Z}$ coefficient, Franco [13], [14] proposed another parameter for the precise evaluation of torsion, analogous to the $\gamma_{Z}$ coefficient, towards estimating the importance of the global second-order effects due to rotation of the building floors, as well as the magnitude between the first-order and the total rotation displacement of the building. This is the $\gamma_{\theta}$ coefficient, given by Equation 2 . 
$\gamma_{\theta}=\frac{\theta_{I I}}{\theta_{I}}=\frac{1}{1-\frac{\Delta M_{t}}{M_{t, I}}}$

where

$\theta_{\mathrm{I}}=$ First-order rotation (due to torsion) of the building, around a vertical axis;

$\theta_{\mathrm{II}}=$ Final rotation (due to torsion) of the building;

$\mathrm{M}_{\mathrm{t}, \mathrm{I}}=$ Global first-order torsion moment;

$\Delta \mathrm{M}_{\mathrm{t}}=$ Increment of global torsion moment due to the first-order torsional displacements.

It is noticeable that the Equations 1 and 2 are similar, and so are the physical and mathematical concepts. An important difference, however, is that the $\gamma_{\mathrm{Z}}$ coefficient may be considered as a simplified amplification factor for the internal forces (relating $\mathrm{M}_{1}$ e $\mathrm{M}_{2}$ ), while the coefficient $\gamma_{\theta}$ may be a simplified amplification factor for the displacements (specifically to the rotation, relating $\theta_{\mathrm{I}}$ and $\theta_{\mathrm{II}}$ ).

The way $\Delta \mathrm{M}_{\mathrm{t}}$ is calculated, however, requires a special attention. The second-order internal forces due to the rotation of the building's horizontal planes are functions of the eccentricities between the top and the bottom of each column, which are misaligned after rotation. Figure 2 illustrates one column in the situation of floor rotation.

a)

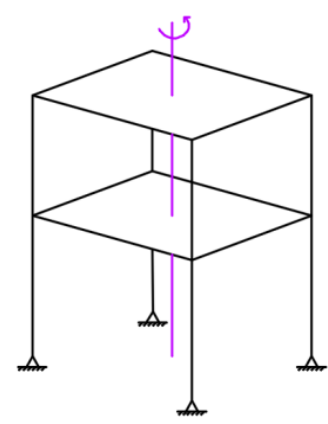

b)

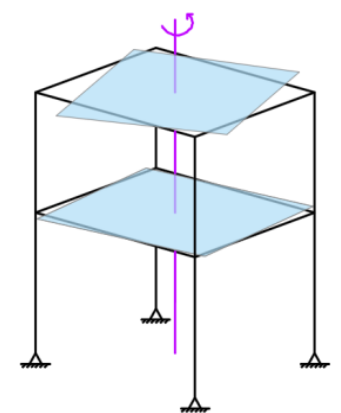

c)

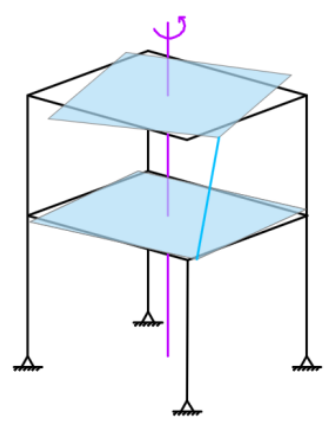

Figure 2. a) Torsional moment applied at a building. b) Rotation of the building's floor. c) Displacement of the highlighted column.

Considering the eccentricity and the vertical load at the ends of a column (Figure 3 ), it is noticeable that an incremental internal force takes place due to the floor rotation. This is the flexural moment observed through the column length and its associated second-order internal force is due to the building displacement. This internal force can also be considered as an increment of the first-order internal force.

a)

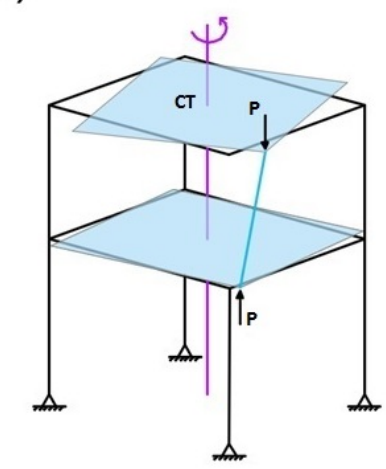

b)

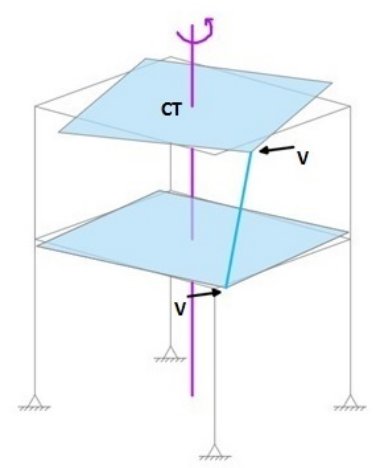

c)

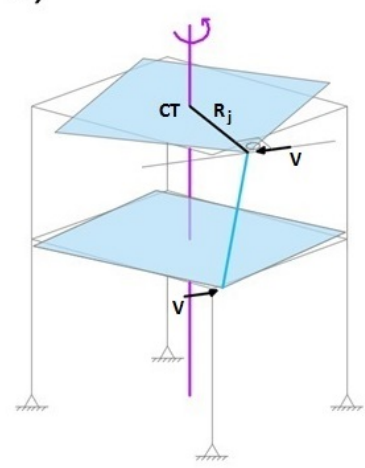

Figure 3. a) Eccentricity between vertical forces. b) Notional forces V. c) Distance R between the column and the CT. 
For the purpose of taking in account the internal forces in all column elements, Franco [13] uses the term $\Delta \mathrm{M}_{\mathrm{t}}$. This is done employing the P- $\Delta$ method, when considering that the flexural moment in each column, caused by the eccentricity between vertical loads $\mathrm{P}$, can be replaced by a horizontal force couple, defined as notional forces $\mathrm{V}$, that causes an equal flexural moment in that element. Furthermore, for each force $V$, there is a term $\Delta M_{t}=V \times R_{j}$, where $R_{j}$ is the distance between the column $\mathrm{j}$ position to the center of twist (CT) of the floor, as illustrated in Figure 3 . The expression "center of twist", or "twist center", is used by Franco, differently from others authors, for example Wight and MacGregor [2], that define it as "center of rotation". The sum of these terms, for every column, results in the total $\Delta \mathrm{M}_{\mathrm{t}}$ of the building.

Franco [14] formulated an expression for $\Delta \mathrm{M}_{\mathrm{t}}$ as a function of the building global characteristics, given by Equation 3 .

$$
\Delta M_{t}=\frac{\bar{P} R^{2} \theta_{I}}{H}
$$

where:

$\bar{P}=$ Total vertical load of the building;

$\mathrm{R}=$ Radius of gyration of the floor masses, related to the CT of that floor;

$\theta_{\mathrm{I}}=$ Global first-order rotation at the top of the building;

$\mathrm{H}=$ Total building height.

Equation 3 allows the calculation of the internal forces increment due to the rotation of the building as a function of its total vertical loading $\bar{P}$, its total height $\mathrm{H}$, the $\mathrm{R}$ parameter, and the first-order rotation $\theta_{\mathrm{I}}$. Employing all these variables, it is possible to obtain $\gamma_{\theta}$.

Note the term $\theta_{\mathrm{I}}$, as defined above, is a result of the first-order structural analysis of the building. This depends not only on the torsional stiffness of each column, shear cores, shear walls, or any other structural element, but also on the interaction of these elements themselves and those in each floor of the building, in a global sense. This means that the $\theta_{\mathrm{I}}$ result reflects the structural model used.

Furthermore, it should be emphasized that the denomination "radius of gyration" was originally used by Franco [13], but should not be confused with the traditional definition of radius of gyration of a surface, which mathematically is the square root of the ratio between the inertia moment and the area of the surface. The definition used here refers to a body composed of various discrete particles (in this case, the particles are the points associated with each column in the building).

In the analytical development presented by Franco [13], the radius of gyration of the system is calculated for a given floor. $P_{j}$ is the normal force in each column $j$, and $R_{j}$ is the distance of each column to the CT of the floor, calculated by Equation 4 .

$$
R=\sqrt{\frac{\sum P_{j} \cdot R_{j}^{2}}{\sum P_{j}}}
$$

The center of twist (CT) of a floor, in turn, is defined as the geometric point of the building's floor that does not undergoes as translational movement when there is a global twisting displacement. If a horizontal force is applied at this point, there will be only translational displacement, with no rotation. If the floor is symmetrical in two orthogonal directions (regarding geometry and structural elements), it is easy to conclude that the $\mathrm{CT}$ will be at the geometrical center of the floor. In non-symmetrical buildings, the CT may be calculated with the stiffness of each bracing structural element, or through the interpretation of the displacements in the case of a pure torsional loading of the structure.

After determining the CT position in each floor, there could be defined a vertical twist axis, if the building is regular (that is, the building has the same story plan repeated along its height). If it is irregular (different story plans in different floors), an averaged vertical twist axis may be considered as an approximation.

The position of the CT will depend on the geometric and stiffness characteristics of the building. It may be estimated analytically, using some hypotheses as simplification, through a weighted average between the position of each element and their stiffness, in each direction, considering all bracing elements. This is sometimes done in buildings with shear walls and shear cores, ignoring the contribution from beam-columns frames (Wight e MacGregor [2]).

On the other hand, if all the aforementioned structural elements are considered, the analytical calculation of the CT position may be highly complex. Franco [14] indicates a second way to determine this point location: through the 
geometric interpretation of the displacements of the building in a pure torsional loading situation. In this case, with the nodal displacements obtained by the structural analysis, it is possible to determine the geometrical point that did not present translational movement, considering the influence of all structural elements in the model. A more detailed description of this methodology, which may be regarded as more adequate than the one presented by Wight $\mathrm{e}$ MacGregor [2], may be found in Andrade et al. [15].

\section{ON THE RESTRICTION USAGE OF THE $\gamma_{Z}$ COEFFICIENT REGARDING TORSION IN BUILDINGS}

The use of the $\gamma_{Z}$ coefficient in current Brazilian design practice is a procedure already established and guided according to ABNT NBR 6118:2014 [5]. As pointed previously, its main hypothesis is the consideration of geometrical progression among the increments of second-order forces.

According to Vasconcelos [16], this premise is valid for $\gamma_{Z}$ coefficient values up to 1.3. However, the author also discusses some exception cases, where such hypothesis may be only partially valid, or even not applicable. Among those situations, one is especially relevant for this study: frames submitted to torsion.

As discussed by Covas [17], the $\gamma_{Z}$ coefficient was originally formulated considering regular structures, that is, multi-story buildings with regular floor height, the same inertia and stiffness for columns, equal cross-section for beams, and the same boundary condition. The author also comments on the importance to design the building so that the resulting forces are aligned with the twist center, but recognize that this is not always possible. Furthermore, he additionally highlights that a precise limit to the building rotation for the admissible use of the $\gamma_{Z}$ coefficient might be hard to define.

It is notorious that the non-regularity cases listed before will make the $\gamma_{Z}$ values gradually deviate from a more accurate result. Hence, the effects due to the building rotation are not completely considered by the $\gamma_{Z}$ coefficient, especially if they are particularly relevant.

When there is a rotation about the vertical axis of a building, the eccentricity between the top and bottom of the structure will not be in the same direction as the external resultant force (Figure 4). This means that each column will present a different eccentricity. Vasconcelos [16] affirms prominently that, because of this rotation, it will not be possible to guarantee that a magnification factor between the first and second-order internal forces will be constant throughout the whole structure. Vieira et al. [8], as already mentioned, explicitly indicate the inefficiency of the $\gamma_{Z}$ coefficient when the critical instability mode has a torsional shape.

a)

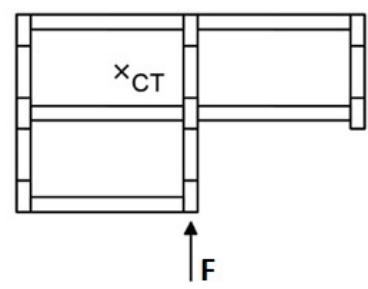

b)

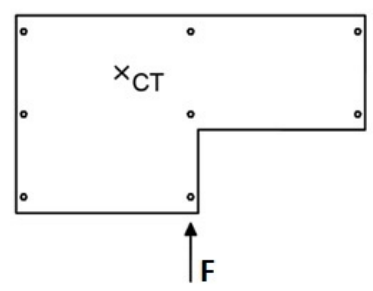

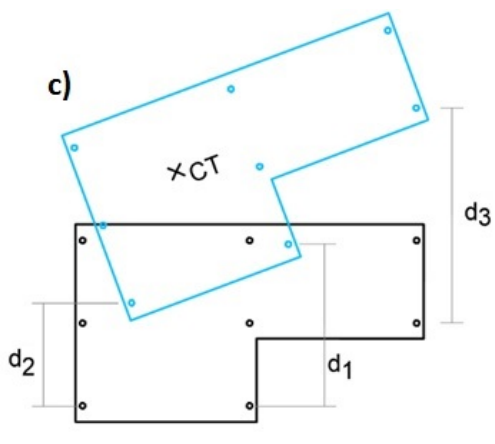

$d_{3}$

Figure 4. a) Force F at a building`s floor with center of twist CT. b) Simplification of the building`s floor. c) Structural elements presenting different eccentricities.

Finally, it should be noticed that even a symmetrical and trivial building might be subjected to torsion because the ABNT NBR 6123:1988 [18] code states the need to verify the effects due to eccentricities considering the direction of the resultant wind forces related to the geometrical axis of the building.

In addition to the discussion above, some numerical examples regarding the representation of torsional effects with the $\gamma_{Z}$ coefficient are presented in section 5.5 of this paper. 


\section{METHODOLOGY}

\subsection{Model description}

As explained previously, the main purpose of this work is to discuss the torsional effects in concrete buildings, to evaluate the $\gamma_{\theta}$ coefficient as an estimating parameter of the global second-order effects due to torsion, and to measure the sensitivity of the $\gamma_{Z}$ coefficient to these effects. The analyses used seven different buildings, divided in two categories:

a) Regular buildings: five models, named Buildings 1 to 5 (Figure 5);

b) Irregular buildings: two models, named Building 6 and 7 (Figure 6).

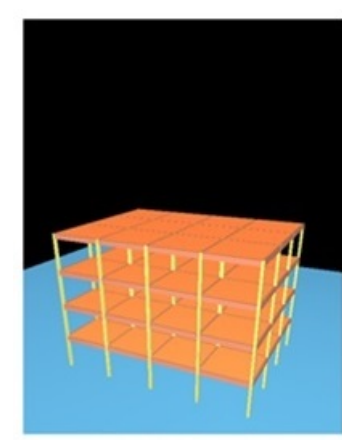

Building 1

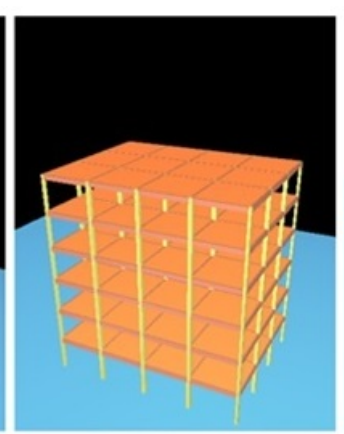

Building 2

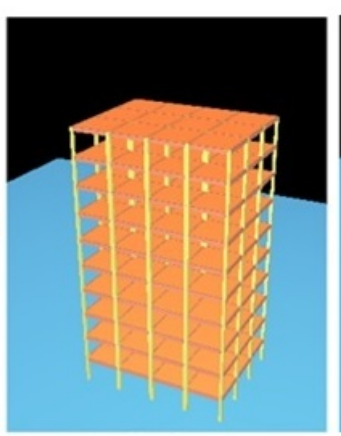

Building 3

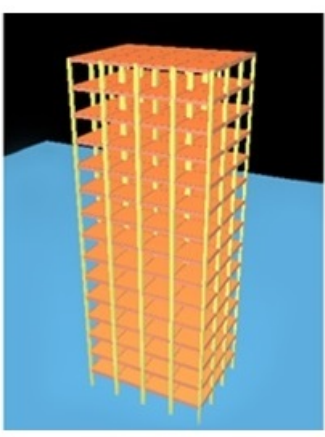

Building 4

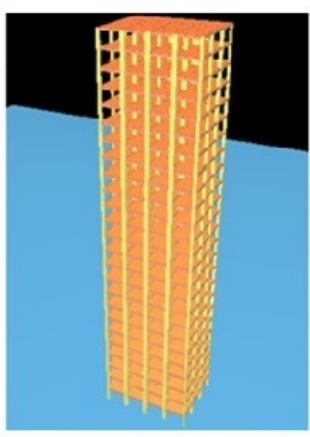

Building 5

Figure 5. Regular buildings.

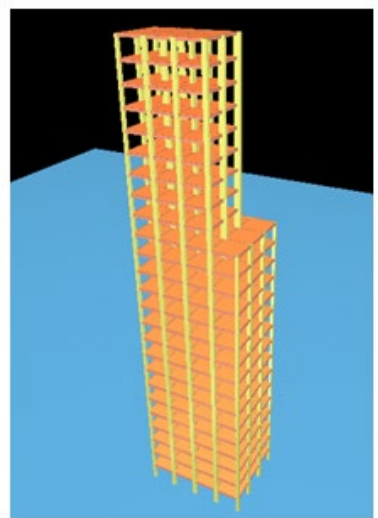

Building 6

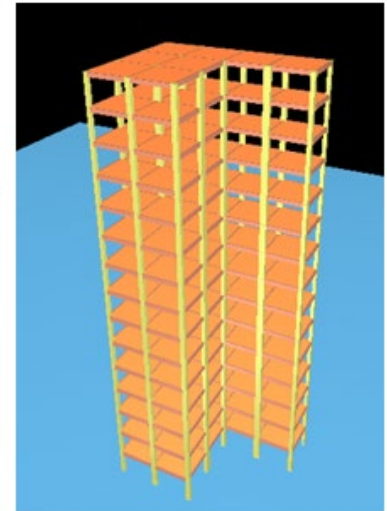

Building 7

Figure 6. Irregular buildings.

The five regular buildings have similar geometry, but different height and number of stories. Each story has a rectangular shape, measuring $13 \mathrm{~m}$ x $17 \mathrm{~m}$, with double symmetry. The story height is $3 \mathrm{~m}$, beams have uniform crosssection and slabs, the same thickness. However, columns present different cross-sections according to each building total height. All structural elements present sections that are design-compatible to dead, live and wind loads. Each regular building has the following height: Building 1 has 4 stories (12 m tall); Building 2 has 6 stories (18 m tall); Building 3 has 10 stories ( $30 \mathrm{~m}$ tall); Building 4 has 15 stories (45 m tall); and the Building 5 has 25 stories (75 m tall).

The two irregular buildings, in turn, present the following characteristics: Building 6 has 25 stories ( $75 \mathrm{~m}$ tall, with a reduced story size starting at the $16^{\text {th }}$ floor); and the Building 7 has 15 stories (45 m tall, with an L-shaped floor).

Initially, the final rotation obtained by the $\gamma_{\theta}$ coefficient, which is a simplified approach, was compared with the final rotation obtained by the P- $\Delta$ method. The later was considered as the reference value, as it was calculated from a more precise method. 


\subsection{Remarks on the torsional load}

All the five regular building models were submitted to two distinct torsional loading cases, simultaneously to the usual dead and live loads (Figure 7): (a) Distributed torsional force couples (applied to each floor); and (b) Single torsional force couple (applied at the top).
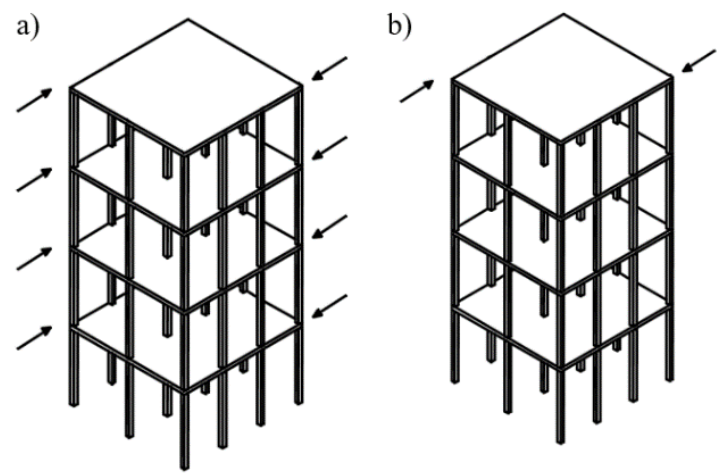

Figure 7. a) Distributed torsion couples. b) Single torsion couple.

The structural analysis considering the first torsional loading situation (distributed couples) will henceforth be referred as first analysis, and the second torsional loading type will be referred as second analysis.

An important remark is that second-order effects are tightly connected to the structure's nodal displacements, which are different according to the torsional loading condition. A single torsional moment (or, equivalently, a couple) applied at the top floor is more consistent with the hypothesis of proportional increments of internal forces (as already discussed in the context of the $\gamma_{Z}$ coefficient). However, this was not the procedure followed by Franco [13], [14], that applied distributed couples.

Because of that, it is proposed the investigation of how the change in couples' distribution and the consequent displacement of the building will affect the $\gamma_{\theta}$ coefficient. Furthermore, by observing the changes in the frame's structure at the façade of the building studied by Franco [14], it seems that as the frame's displacement modifies, so does the error (the difference between the $\gamma_{\theta}$ coefficient and the P- $\Delta$ method results), even if only slightly.

Consequently, this observation has inspired the investigation of how the models would respond to a change in its displacement because of the different torsional loading applied. Thus, all regular buildings were analyzed twice, by changing the acting torsional couple.

\subsection{Software used}

The CAD/TQS software package, which is widely known and utilized by professional offices in Brazil, was used in this work and presents many computational modules for different steps of structural design (modeling, analysis, detailing and BIM). However, its use in this study was restricted to the structural analysis. It is fact that several other structural analysis softwares might have been used, especially those based on Finite Element Method, but CAD/TQS was chosen due to its reliability and ease of use when dealing with concrete framed buildings.

It should be observed that the $\gamma_{Z}$ coefficient determination is an automated process in CAD/TQS, which is not the case for the $\gamma_{\theta}$ coefficient. In fact, no structural analysis software contains such feature, and all the necessary calculation presented on this work was done through the evaluation of the analysis output results and subsequent manual treatment of the necessary values. The process, although arduous, is relatively simple, and may be easily automated. Andrade et al. [15] describe this process in detail.

Others important aspects were subjected to complementary investigations, such as the displacement profile of the buildings, and the sensitivity of the $\gamma_{Z}$ coefficient to the torsional couple distribution. The following section presents and discusses the results. 


\section{RESULTS AND COMMENTS}

\section{$5.1 \gamma_{\theta}$ coefficient evaluation of regular buildings}

The $\gamma_{\theta}$ coefficient was calculated for each regular building (Models 1 to 5 ) by using Equations 2 to 4 . The structure's final rotation will be the product between the first-order rotation and the $\gamma_{\theta}$ coefficient. This is the proposed simplified approach. The final rotation will also be evaluated and compared by the P- $\Delta$ method, which is accepted as a more accurate process.

Once more, it is relevant to emphasize a remark about the radius of gyration (R) and the twist center (CT) of the floor, which are essential to the $\gamma_{\theta}$ coefficient determination. For each building, the $\mathrm{R}$ variable was obtained considering the axial force of each column and its positions relative to the CT of the building. As the stories of buildings 1 to 5 are symmetrical, the CT will be positioned at the geometrical center of the floor (and the twist axis will be a vertical line along all the structure). For a better understanding, the calculations associated to the building 1 will be presented. For the others, a summary of the results is provided.

Because all the floors of the building are identical (regarding to loadings and to the position of structural elements, due to its double symmetry), it is possible to obtain $\mathrm{R}$ with the information of only one of the stories (if all the stories were considered, the numerator and the denominator would change proportionally). Thus, $\mathrm{R}$ will be calculated, for building 1, by using Equation 4 and the data provided in Table 1:

$R=\sqrt{\frac{\sum_{j=1}^{r} P_{j} R_{j}^{2}}{\sum_{j=1}^{r} P_{j}}}=\sqrt{\frac{394067,249}{8951,3}}=6.635 \mathrm{~m}$

Table 1. Column loading and column position relative to the floor's CT-Building 1.

\begin{tabular}{cccc}
\hline Column & $\mathbf{P}_{\mathbf{j}}(\mathbf{k N})$ & $\mathbf{R}_{\mathbf{j}}(\mathbf{m})$ & $\mathbf{P}_{\mathbf{j}} \mathbf{R}^{\mathbf{2}}$ \\
\hline $\mathbf{1}$ & 190.4 & 10.53 & 21095.480 \\
\hline $\mathbf{2}$ & 380.9 & 7.59 & 21957.363 \\
\hline $\mathbf{4}$ & 345.6 & 6.28 & 13638.401 \\
\hline $\mathbf{5}$ & 390.4 & 7.52 & 22080.996 \\
\hline $\mathbf{6}$ & 201.1 & 10.42 & 21844.173 \\
\hline $\mathbf{7}$ & 383.2 & 8.70 & 28999.346 \\
\hline $\mathbf{8}$ & 760.9 & 4.71 & 16902.444 \\
\hline $\mathbf{9}$ & 682.3 & 2.01 & 2750.157 \\
\hline $\mathbf{1 0}$ & 758.6 & 4.60 & 16027.456 \\
\hline $\mathbf{1 2}$ & 377.1 & 8.57 & 27718.600 \\
\hline $\mathbf{1 3}$ & 369.1 & 8.76 & 28303.693 \\
\hline $\mathbf{1 4}$ & 763.9 & 4.82 & 17737.725 \\
\hline $\mathbf{1 5}$ & 682.6 & 2.24 & 3438.201 \\
\hline $\mathbf{1 6}$ & 754.9 & 4.70 & 16708.868 \\
\hline $\mathbf{1 7}$ & 390.6 & 8.63 & 29103.936 \\
\hline $\mathbf{1 8}$ & 198.5 & 10.67 & 22592.119 \\
\hline $\mathbf{1 9}$ & 393.4 & 7.79 & 23870.118 \\
\hline $\mathbf{2 0}$ & 347.5 & 6.52 & 14766.463 \\
\hline $\mathbf{T o t a l}$ & 386.7 & 7.70 & 22917.809 \\
\hline & 193.6 & 10.57 & 21613.901 \\
\hline
\end{tabular}

The first-order rotation obtained through the structural analysis of building 1 in CAD/TQS is $\theta_{\mathrm{I}}=1.46 \times 10^{-3} \mathrm{rad}$ with a respective total torsional moment loading (as distributed couples) of $\mathrm{M}_{\mathrm{t}, \mathrm{I}}=672 \mathrm{kN}$.m. Hence, considering the complementary information:

$\mathrm{H}=12 \mathrm{~m}$

$\bar{P}=8951.3 \mathrm{kN}$

$\theta_{I, n}=1.46 \times 10^{-3} \mathrm{rad}$ 
$\Delta M_{t}=\frac{\bar{P} R^{2} \theta_{I, N}}{H}=\frac{8951.3 \cdot 6.635^{2} \cdot 0.00146}{12}=47.945 \mathrm{kN} . \mathrm{m}$

This is the expected increment of torsional moment $\Delta \mathrm{M}_{\mathrm{t}}$.

Admitting the applied first-order moment $M_{t, I}=672 \mathrm{kN} . \mathrm{m}$, the $\gamma_{\theta}$ coefficient is obtained:

$\gamma_{\theta}=\frac{1}{1-\left(\frac{\Delta M_{t}}{M_{t, I}}\right)}=\frac{1}{1-\left(\frac{47.945}{672}\right)}=1.0768$

The $\gamma_{\theta}$ coefficient indicates that the final rotation (taking into account second-order effects) is approximately 1.0768 times larger than the first-order rotation. The value for the rotation obtained by the P- $\Delta$ method, also performed in CAD/TQS, is $\theta_{\text {II P- } \Delta}=1.637 \times 10^{-3} \mathrm{rad}$. The following comparison is presented:

Final rotation at the top, provided by $\gamma_{\theta}: \theta_{\mathrm{I}, \mathrm{n}} \cdot \gamma_{\theta}=0.00146 \times 1.0768=1.572 \times 10^{-3} \mathrm{rad}$

Final rotation at the top, provided by P- $\Delta$ method: $\theta_{\text {II P- } \Delta}=1.637 \times 10^{-3} \mathrm{rad}$

Error $=(0.001572-0.001637) / 0.001637 \cong-4.0 \%$

The same methodology is used for the remaining four regular buildings. Table 2 summarizes the results. Notably, the second-order rotation values obtained using the $\gamma_{\theta}$ coefficient were similar to the rotation presented by the P- $\Delta$ method. The maximum error found was $10.3 \%$ (on the nonconservative side) and the average error was $6.06 \%$. Franco [14] also compares the values of the same parameter analyzing one building (with modifications on frames in its façade) with the P- $\Delta$ method and indicates error values of $-0.6 \%,-1.6 \%$ and $-5.5 \%$.

Table 2. $\gamma_{\theta}$ coefficient calculation and comparison with $\mathrm{P}-\Delta$ method (first analysis).

\begin{tabular}{|c|c|c|c|c|c|}
\hline & Building 1 & Building 2 & Building 3 & Building 4 & Building 5 \\
\hline n (number of stories) & 4 & 6 & 10 & 15 & 25 \\
\hline $\mathrm{H}(\mathrm{m})$ & 12 & 18 & 30 & 45 & 75 \\
\hline P Total $(\mathrm{kN})$ & 8951.3 & 13614.3 & 23182.8 & 35919.92 & 64310.2 \\
\hline $\mathrm{R}(\mathrm{m})$ & 6.635 & 6.672 & 6.674 & 6.716 & 6.726 \\
\hline$\theta_{\mathrm{I}}(\mathrm{rd})$ & $1.46 \times 10^{-3}$ & $1.88 \times 10^{-3}$ & $3.04 \times 10^{-3}$ & $5.24 \times 10^{-3}$ & $1.052 \times 10^{-2}$ \\
\hline$\Delta \mathrm{Mt}$ (kN.m) & 47.945 & 63.293 & 104.645 & 188.631 & 408.028 \\
\hline $\mathrm{M}_{\mathrm{t}, \mathrm{I}}(\mathrm{kN})$ & 672 & 1008 & 167 & 2497.5 & 4162.5 \\
\hline$\gamma_{\theta}$ & 1.0768 & 1.0670 & 1.0669 & 1.0817 & 1.1087 \\
\hline$\theta_{\text {II }}(\mathrm{rad})\left(\gamma_{\theta}\right.$ method $)$ & $1.572 \times 10^{-3}$ & $2.006 \times 10^{-3}$ & $3.243 \times 10^{-3}$ & $5.668 \times 10^{-3}$ & $1.166 \times 10^{-2}$ \\
\hline$\theta_{\mathrm{II}}(\mathrm{rad})(\mathrm{P}-\Delta$ method $)$ & $1.637 \times 10^{-3}$ & $2.092 \times 10^{-3}$ & $3.406 \times 10^{-3}$ & $6.100 \times 10^{-3}$ & $1.300 \times 10^{-2}$ \\
\hline Error & $-4.0 \%$ & $-4.1 \%$ & $-4.8 \%$ & $-7.1 \%$ & $-10.3 \%$ \\
\hline
\end{tabular}

Bueno [19], in an analogous procedure, compares the second-order moments obtained applying the $\gamma_{Z}$ coefficient and the P- $\Delta$ method for three buildings. For this purpose, the author adopts a ratio named RM2M1, which is available in CAD/TQS software, and provides a comparison between the first and the second-order moments. The first building shows small error values such as $+0.1 \%$ up to $+1 \%$ (on the conservative side). For the second one, that presents torsional effects, there are greater error values such as $4.9 \%$. And for the last one, which $\gamma_{Z}$ parameter is greater than 1.3 (the limit value recommended by the standard code ABNT NBR 6118:2014 [5]), the error is 14.5\%.

So, the error values obtained in the present study were considered acceptable, taking into account the simplified nature of the method for the determination of the second-order rotation. Thus, the $\gamma_{\theta}$ coefficient may be regarded as an adequate parameter for the evaluation of susceptibility to second-order rotations. 


\section{$5.2 \gamma_{\theta}$ coefficient evaluation of regular buildings with different torsional loading}

As described before, buildings 1 to 5 are analyzed twice, now with a single torsion couple applied at the top floor. This procedure would be expected as the most consistent with the fundamental premises of the $\gamma_{\theta}$ coefficient. As before, the results are compared with those obtained by the more accurate $\mathrm{P}-\Delta$ analysis.

Table 3 summarizes the results from the second analysis, similarly to Table 2. It is important to highlight that the rotation displacements magnitude continues in the same level as in previous analysis, but the results are now closer to the reference values of the $\mathrm{P}-\Delta$ method. Now, the greatest error is $4.0 \%$. These results confirm the $\gamma_{\theta}$ coefficient applicability and accuracy as an evaluation procedure for torsional effects.

The dependence of the $\gamma_{\theta}$ coefficient on the loading distribution is discussed again in the next section, devoted to the angular displacement profile of the building.

Table 3. $\gamma_{\theta}$ coefficient calculation and comparison with $\mathrm{P}-\Delta$ method (second analysis).

\begin{tabular}{cccccc}
\hline & Building 1 & Building 2 & Building 3 & Building 4 & Building 5 \\
\hline$\gamma_{\theta}$ & 1.0768 & 1.0670 & 1.0669 & 1.0817 & 1.1087 \\
\hline$\theta_{\text {II }}(\mathrm{rad})\left(\gamma_{\theta}\right.$ method $)$ & $1.407 \times 10^{-3}$ & $1.913 \times 10^{-3}$ & $3.294 \times 10^{-3}$ & $6.020 \times 10^{-3}$ & $1.313 \times 10^{-2}$ \\
\hline$\theta_{\text {II }}(\mathrm{rad})(\mathrm{P}-\Delta$ method $)$ & $1.374 \times 10^{-3}$ & $1.865 \times 10^{-3}$ & $3.189 \times 10^{-3}$ & $5.830 \times 10^{-3}$ & $1.263 \times 10^{-2}$ \\
\hline Error & $2.4 \%$ & $2.5 \%$ & $3.3 \%$ & $3.3 \%$ & $4.0 \%$ \\
\hline
\end{tabular}

\subsection{Evaluation of the angular displacement profile}

The angular displacement (rotation) profiles of buildings 1 to 5 were analyzed in order to investigate if the different loading distributions produce modification on them. All the buildings of the first analysis (with distributed torsion couples) present a similar behavior: a variation of the inter-story rotation displacement along the height. For the second analysis (with torsion couples applied only at the top floor), all the buildings presented a quasi-constant increment in rotation between any two floors. Figures 8 and 9 show the plots of the angular displacement per floor, resulting from the two analyses of building 4 .

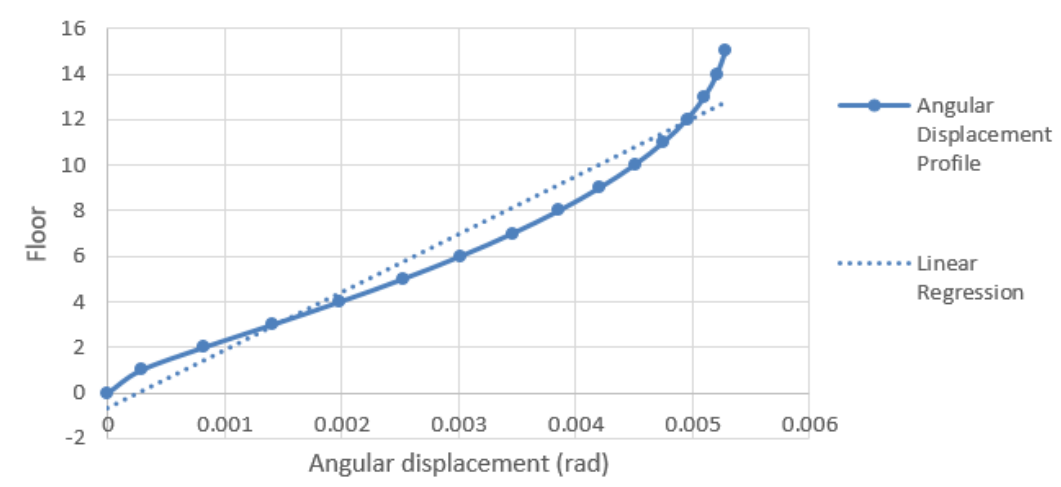

Figure 8. Angular displacement at each floor (building 4 and first analysis).

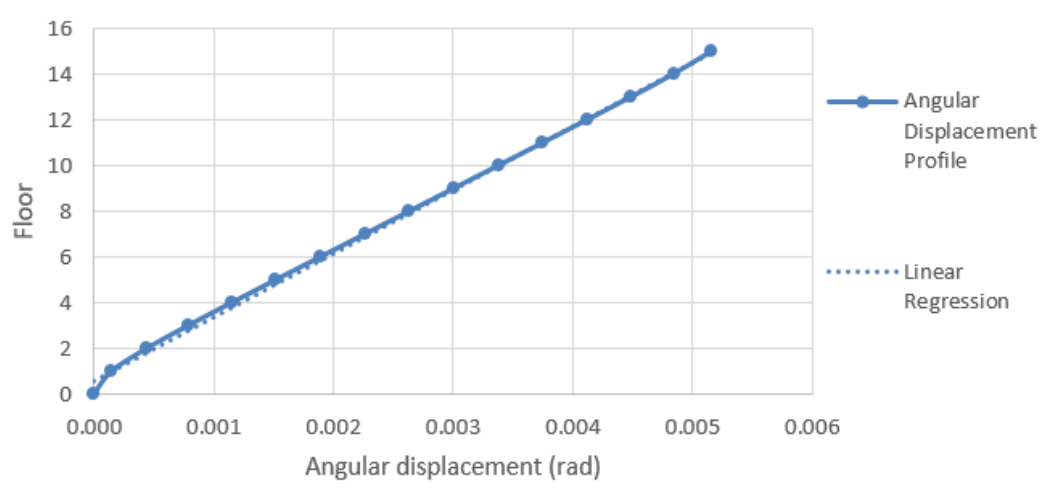

Figure 9. Angular displacement at each floor (building 4 and second analysis). 
At first sight, this can be an influence factor on $\gamma_{\theta}$ coefficient values, because the angular displacements between floors, for a given second-order analysis iteration, are closely related with the distribution of new internal forces in the structure and with the consideration of the geometrical progression (as invariable) between iterations.

The $\gamma_{\theta}$ coefficient makes use of the hypothesis that the ratio of the increment in internal forces is constant between two successive second-order iterations. This is expected only if, for each story, the current distribution of the addition of internal forces is similar as that obtained in the previous iteration. The $\mathrm{P}-\Delta$ method, on the other hand, is fully capable of considering different distribution of internal forces at each iteration, even if those may not follow exactly this hypothesis of constant geometrical progression.

Unchanged variations of angular displacements along the height for each building in the second analysis are probably closer to the situation of similar distributions of incremental internal forces between iterations (eccentricities are almost the same between each floor). At the other hand, the greater variation in displacements between floors in the first analysis are tied to different increment in internal forces between each floor, giving rise to a new distribution of displacement (and internal forces) in the next iteration.

It should be observed that a usual design situation would involve not a single force couple at the top floor, or identical force couples in each story, but different torsion intensities according to the wind action, out-of-plumb horizontal forces and their respective eccentricities to the CT. In reality, the design practice faces an intermediate situation between the first and second analyses discussed previously.

In addition, it should be noticed that even for usual horizontal forces loadings, different buildings may present different profile displacement shapes. Hence, it is important to study how this may be related to the variation in error values between the $\gamma_{\theta}$ coefficient and the P- $\Delta$ method.

\section{$5.4 \gamma_{\theta}$ coefficient evaluation of irregular buildings}

Sections 5.1 and 5.2 covered the regular buildings (models 1 to 5 ) to evaluate the response of the $\gamma_{\theta}$ coefficient. At this point, the results from irregular buildings (models 6 and 7) are presented. Table 4 shows the values of the secondorder final rotation of the structure, using the $\gamma_{\theta}$ coefficient procedure and the $\mathrm{P}-\Delta$ method. Once again, a good convergence between the results is evident, with a maximum error of $5.3 \%$.

For all the previous analyses, it is possible to conclude that the evaluation procedure considering the $\gamma_{\theta}$ coefficient presented an adequate estimate regarding both regular and irregular buildings.

Table 4. $\gamma_{\theta}$ coefficient calculation and comparison with P- $\Delta$ method (irregular buildings).

\begin{tabular}{ccc}
\hline & Building 6 & Building 7 \\
\hline$\gamma_{\theta}$ & 1.1001 & 1.0950 \\
\hline$\theta_{\text {II }}(\mathrm{rad})\left(\gamma_{\theta}\right.$ method $)$ & $1.221 \times 10^{-2}$ & $6.910 \times 10^{-3}$ \\
\hline$\theta_{\mathrm{II}}(\mathrm{rad})(\mathrm{P}-\Delta$ method $)$ & $1.290 \times 10^{-2}$ & $7.230 \times 10^{-3}$ \\
\hline Error & $-5.3 \%$ & $-4.5 \%$ \\
\hline
\end{tabular}

\section{$5.5 \gamma z$ coefficient behavior under extra torsional load action}

The behavior of the $\gamma_{Z}$ coefficient is now investigated analyzing the model 4 , in the absence or presence of distributed torsional couples acting simultaneously with the usual design loads (live, dead and wind loads). Table 5 summarizes the results.

Table 5. $\gamma z$ coefficient values in absence or presence of torsional couples.

\begin{tabular}{|c|c|c|}
\hline & $\gamma \mathrm{z}$ in absence of couples & $\gamma z$ in presence of couples \\
\hline Case $1\left(90^{\circ}\right.$ wind $)$ & \multirow{2}{*}{1.174} & \multirow{2}{*}{1.174} \\
\hline Case $2\left(270^{\circ}\right.$ wind $)$ & & \\
\hline $\begin{array}{c}\text { Case } 3\left(0^{\circ} \text { wind }\right) \\
\text { Case } 4\left(180^{\circ} \text { wind }\right)\end{array}$ & 1.153 & 1.153 \\
\hline
\end{tabular}

There was no difference in $\gamma_{Z}$ coefficient values in the presence of an extra rotation due to torsion. This happens because the building has symmetrical floors, and the "extra" eccentricity caused by the rotation in one side of the 
building is balanced by the other detected on the opposite side, that has an eccentricity in the reverse direction. Then, the "extra" displacements due to torsion cancel each other.

Despite that the $\gamma_{Z}$ coefficient is a term used to measure the magnitude of global second-order effects, in this case, with the presence of the torsional couples that cause greater global second-order effects and a top story rotation increment of approximately $8 \%$ (according to the $\gamma_{\theta}$ coefficient), the $\gamma_{Z}$ coefficient is incapable to detect these effects.

However, the building's floors rotations due to torsional moment (caused either by horizontal couples or, equivalently, by an eccentricity between resultant external forces and the twist center) will cause a force redistribution on the elements of bracing frames to resist the new load. This means that greater moments in the structural elements, due to the rotation and its respective second-order effects, may occur without significant change of the $\gamma_{Z}$ coefficient. This clearly shows the importance of examining specifically the global second-order effects due to torsion and the use of the $\gamma_{\theta}$ coefficient.

Finally, it is important to highlight that the discussion of the preceding paragraphs refers to buildings with uniform distributed loading in the area of the floors (especially the idea about the displacements equilibrium due to eccentricities). When the floors have different vertical gravity loads, depending on the area, the $\gamma_{z}$ coefficient will change more prominently, because the opposite sides' eccentricity will not compensate each other. As discussed in section 3 , effects due to torsion may not be adequately considered by the $\gamma_{Z}$ coefficient, and its use as an amplification factor in cases where torsion is significant, may result inaccurate and unsatisfactory.

To better understand this inadequate sensitivity of the $\gamma_{Z}$ coefficient due to rotations, Table 6 shows the values of $\gamma_{Z}\left(\gamma_{Z X}\right.$ in the $\mathrm{X}$ direction and $\gamma_{Z Y}$ in the $\mathrm{Y}$ direction) and $\gamma_{\theta}$ for each one of the five buildings studied in section 5.1, besides the values of $\theta_{\mathrm{I}}$ (first-order rotation), $\theta_{\mathrm{II}}$ P- (second-order rotation calculated by the $\mathrm{P}-\Delta$ method) and the ratio $\theta_{\mathrm{I}} / \theta_{\text {II P }-\Delta \text {. }}$

Table 6. $\gamma_{\theta}$ coefficient calculation and comparison with P- $\Delta$ method (second analysis).

\begin{tabular}{cccccc}
\hline & Building 1 & Building 2 & Building 3 & Building 4 & Building 5 \\
\hline$\gamma_{\mathrm{ZX}}$ & 1.133 & 1.190 & 1.180 & 1.153 & 1.219 \\
$\gamma_{\mathrm{ZY}}$ & 1.134 & 1.170 & 1.145 & 1.174 & 1.259 \\
$\gamma_{\theta}$ & 1.0768 & 1.067 & 1.0669 & 1.0817 & 1.1087 \\
\hline$\theta_{\mathrm{I}}(\mathrm{rad})$ & $1.460 \times 10^{-3}$ & $1.880 \times 10^{-3}$ & $3.040 \times 10^{-3}$ & $5.240 \times 10^{-3}$ & $1.052 \times 10^{-2}$ \\
\hline$\theta_{\mathrm{II}}(\mathrm{rad})(\mathrm{P}-\Delta$ method $)$ & $1.640 \times 10^{-3}$ & $2.092 \times 10^{-3}$ & $3.406 \times 10^{-3}$ & $6.100 \times 10^{-3}$ & $1.300 \times 10^{-2}$ \\
\hline$\theta_{\mathrm{I}} / \theta_{\mathrm{II}}$ & 1.1211 & 1.1126 & 1.1204 & 1.1640 & 1.2361 \\
\hline
\end{tabular}

Figure 10 presents the curves of each of these variables in the first analysis (distributed couples along the height). The $\gamma_{\theta}$ coefficient curve exhibits a similar tendency as the ratio $\theta_{\mathrm{I}} / \theta_{\text {II P- }-\Delta}$. The profile of the $\gamma_{Z}$ coefficient, however, is considerably different.

Similarly, Figure 11 shows the curves for the second analysis (single couple at the top). The general conclusion is the same: the $\gamma_{\theta}$ coefficient curve is the only one with a similar shape as the results from the P- $\Delta$ method, differently from the $\gamma_{Z}$ coefficient values.

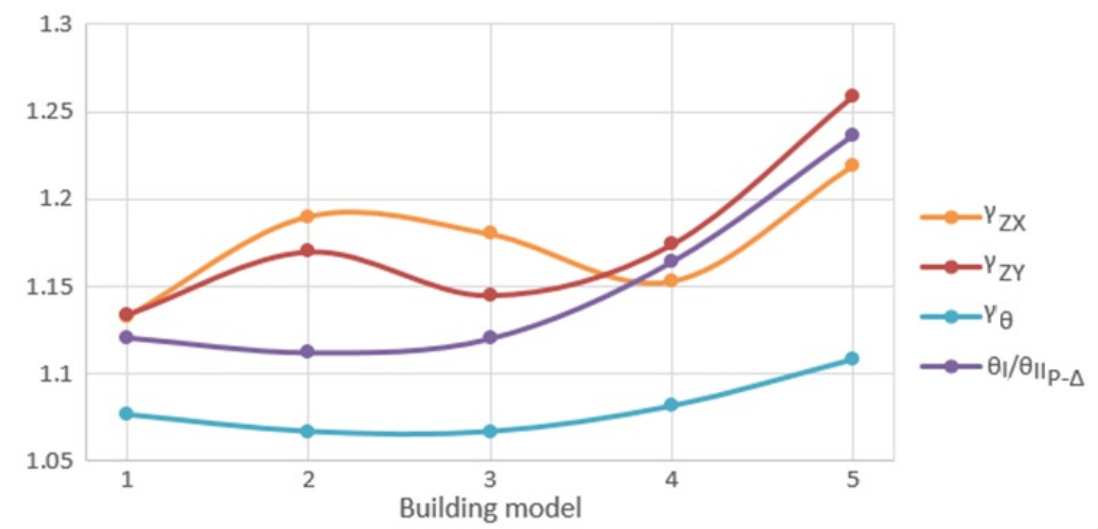

Figure 10. Comparison on the parameters behavior (first analysis). 


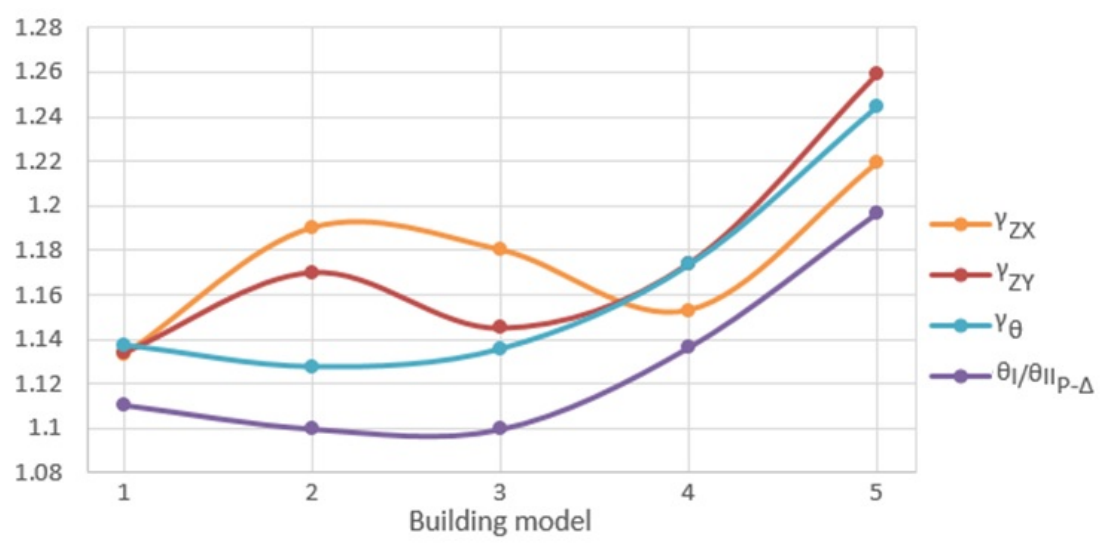

Figure 11. Comparison on the parameters behavior (second analysis).

As a final note, it is important to emphasize that the numerical comparison of internal forces in structural elements, in the presence or absence of torsional moments, was not discussed in this study. Obviously, there is a significant modification in the internal forces distribution between these two cases. This paper did not aim to study the change in internal forces distribution, but to investigate the global behavior of the structure and the instability parameters evaluated.

\section{CONCLUSIONS}

This paper discusses the $\gamma_{\theta}$ coefficient use and its calculation, another ingenious development from Professor Engineer Mario Franco, as estimator criteria for the magnitude of the second-order global rotation of buildings due to torsion effects. This is a parameter analogous to the $\gamma_{Z}$ coefficient, but differently from the latter, has been neglected by the technical literature.

The global second-order angular displacements from seven different building analyses were evaluated with the use of the software CAD/TQS. They had regular and irregular geometries, and were submitted to two different torsion loadings. The buildings' final rotation (estimated by the $\gamma_{\theta}$ coefficient) was compared with the values obtained using a more accurate analysis, the $\mathrm{P}-\Delta$ method. The error found between both procedures ranged from $1.7 \%$ to $10.6 \%$, which is regarded as acceptable for a simplified method.

Other complementary analyses were done, evaluating the rotation displacement profile of the buildings according to the torsional loading distribution. The objective was to verify the sensibility and the completeness (in the sense of the capability to assess any global second-order effect) of the $\gamma_{Z}$ coefficient to rotation displacements, especially when considered regular structures.

Finally, the importance of a measure criteria related to the rotation of structures is highlighted, as a complement to the flexural effects. Currently, the rotation due to torsion is sometimes neglected in the design practice, even if it is always present in buildings, in a high or low level of magnitude.

\section{ACKNOWLEDGMENTS}

The authors are grateful to the TQS Informática Ltda. for providing the software CAD/TQS academic version for UFRN.

\section{REFERENCES}

[1] P. B. Fusco and M. Onishi, Introdução à engenharia de estruturas de concreto. São Paulo: Cengage, 2017.

[2] J. K. Wight and J. G. Macgregor, Reinforced concrete: mechanics and design, 5th ed. Upper Saddle River: Pearson Prentice Hall, 2009.

[3] A. Kimura, Informática aplicada a estruturas de concreto armado, 2. ed. São Paulo: Oficina de Textos, 2018.

[4] W. J. Z. Moncayo, “Análise de segunda ordem global em edifícios com estrutura de concreto armado,” M.S. thesis, EESC, USP, São Carlos, SP, 2011. http://dx.doi.org/10.11606/D.18.2011.tde-19042011-085946. 
[5] Associação Brasileira de Normas Técnicas. NBR 6118:2014: Projeto de Estruturas de Concreto - Procedimento. Rio de Janeiro: ABNT, 2014.

[6] M. Franco and A. C. Vasconcelos, "Practical assessment of second order effects in tal buildings," in Colloq. CEB-FIP MC90, Rio de Janeiro, 1991, pp. 307-323.

[7] M. Franco and A. C. Vasconcelos, “Avaliação prática dos efeitos de 2a ordem em edifícios altos,” in Coletânea de Trabalhos Sobre Estabilidade Global e Local das Estruturas de Edificios, Instituto de Engenharia de São Paulo, São Paulo: Instituto de Engenharia de São Paulo, 1997, pp. 41-54.

[8] V. V. S. Vieira, S. J. Rodrigues Jr., and L. A. C. M. Veloso, “Análise da estabilidade global de edifícios de concreto armado usando o coeficiente $\gamma Z$,” Rev. IBRACON Estrut. Mater., vol. 10, no. 5, p. 1113-1140, Sept./Oct. 2017, http://dx.doi.org/10.1590/S198341952017000500010.

[9] R. G. Mamone, G. H. Siqueira, and L. C. M. Vieira Jr, "The use of natural period of vibration as a simplified indicator of second-order effects for RC frames," Int. J. Struct. Civ. Eng. Res, vol. 7, no. 1, pp. 15-21, Feb. 2018, http://dx.doi.org/10.18178/ijscer.7.1.15-21.

[10] D. G. Reis, G. H. Siqueira, L. C. M. Vieira Jr, and R. D. Ziemian, "Simplified approach based on the natural period of vibration for considering second-order effects on reinforced concrete frames," Int. J. Struct. Stab. Dyn., vol. 18, no. 5, p. 1-22, Jan. 2018, http://dx.doi.org/10.1142/S0219455418500748.

[11] F. F. Leitão, G. H. Siqueira, L. C. M. Vieira Jr, and S. J. C. Almeida, “Análise dos efeitos globais de segunda ordem em estruturas irregulares em concreto armado utilizando o período natural de vibração," Rev. IBRACON Estrut. Mater. vol. 12, n. 2, p. 408-428, Mar./Apr. 2019, http://dx.doi.org/10.1590/S1983-41952019000200012.

[12] R. N. Cunha, L. A. Mendes, and D. L. N. F. Amorim, "Proposta de critério simplificado para estimar efeitos de segunda ordem em edifícios de concreto armado," Rev. IBRACON Estrut. Mater., vol. 13, n. 2, p. 200-211. 2020, http://dx.doi.org/10.1590/S198341952020000200002.

[13] M. Franco, "Torsion in tall buildings," in 3rd International Conference of High-Performance Concrete, and Performance and Quality of Concrete Structures, Recife, 2002.

[14] M. Franco, “A torção nos edifícios altos,” in Simpósio EPUSP Sobre Estruturas de Concreto, São Paulo, 2003.

[15] R. B. Andrade, P. G. B. Nóbrega, and S. H. S. Nóbrega, "Metodologia para o cálculo de um coeficiente de avaliação dos efeitos de segunda ordem globais de torção," in $61^{\circ}$ Congresso Brasileiro do Concreto CBC2019, Fortaleza, 2019. Accessed: Mar. $22,2019$. [Online]. Available: https://www.researchgate.net/publication/336672173.

[16] A. C. Vasconcelos, “Em que casos não se deve aplicar o Gamaz?,” TQS Docs. 2000. Accessed: Mar. 30 2020. [Online]. Available: $\mathrm{http}: / /$ docs.tqs.com.br/Docs/Details?id=3300\&search=Gamaz\&language=pt-Br

[17] N. Covas, "GamaZ,” TQS Docs. 2009. Accessed: Mar. 30 2020. [Online]. Available: http://docs.tqs.com.br/Docs/Details?id=3306\&search=Gamaz\&language=pt-Br

[18] Associação Brasileira de Normas Técnicas, NBR 6123:1988: Forças devidas ao vento em edificações. Rio de Janeiro: ABNT, 1988.

[19] M. M. E. Bueno, “Avaliação dos parâmetros de instabilidade global em estruturas de concreto armado,” M.S. thesis, ENC, UnB, Brasília, DF, 2009. [Online]. Available: http://www.pecc.unb.br/wp-content/uploads/dissertacoes/M09-2A-Mônica-Bueno.pdf

Author contributions: R. B. Andrade: conceptualization, formal analysis, writing; P. G. B. Nóbrega: conceptualization, methodology, writing, supervision.

Editors: Edgar Bacarji, José Luiz Antunes de Oliveira e Sousa, Guilherme Aris Parsekian. 